\title{
Expression of cell membrane complement regulatory glycoproteins along the normal and diseased human gastrointestinal tract
}

\author{
A E Berstad, P Brandtzaeg
}

\begin{abstract}
BackgroundIAims-Uncontrolled complement activation may be of immunopathological importance in inflammatory diseases of the gastrointestinal tract. Expression of membrane bound factors that regulate complement activation was therefore studied in situ.

Methods-Frozen tissue specimens were obtained from patients with Helicobacter pylori gastritis, coeliac disease, Crohn's disease, or ulcerative colitis, and from histologically normal controls. Sections were examined by immunofluorescence with monoclonal antibodies to protectin (CD59), decay accelerating factor (DAF), and membrane cofactor protein (MCP). Results-Protectin and MCP were widely expressed in normal and diseased mucosae. MCP was generally observed basolaterally on all epithelial cells, whereas apical protectin expression was more intense on the epithelium of normal colonic mucosa than in the normal duodenum $(p=0.001)$. Epithelial DAF and to some extent protectin were upregulated in gastritis, coeliac disease, and inflammatory bowel disease. Areas of the stomach with intestinal metaplasia expressed DAF, unlike the adjacent gastric epithelium. Parietal cells of the gastric body expressed neither protectin nor DAF.
\end{abstract}

Conclusion-Epithelial complement inhibitory molecules were expressed differently at various normal gastrointestinal sites and also in association with mucosal disease, suggesting variable protective potential. Such molecules could play a role in the development of gastric atrophy by protecting areas of intestinal metaplasia. Conversely, parietal cells appeared to be potentially vulnerable targets for complement attack.

(Gut 1998;42:522-529)

Immunohistochemistry and Immunopathology (LIIPAT), Institute of Pathology, University of Oslo, The National Hospital,

Rikshospitalet, Oslo, Norway

A E Berstad

P Brandtzaeg

Correspondence to: Dr A E Berstad, LIIPAT, Rikshospitalet, N-0027 Oslo, Norway.

Accepted for publication 26 November 1997 organisms and other insults. ${ }^{1}$ However, uncontrolled complement activation can lead to tissue damage and thereby be of immunopathological importance in acute and chronic inflammatory diseases of the gastrointestinal tract. Indeed, activated complement has been detected in lesions of inflammatory bowel disease, ${ }^{2-4}$ coeliac disease, ${ }^{5}$ and recently also in Helicobacter pylori gastritis. $^{6}$

Certain complement activation products, notably the C3b fragment and the C5b-7 complex, can on their own - that is, without associated antibody-bind to any nearby cell membrane. ${ }^{7}$ Therefore it is crucial that complement activity is tightly regulated. Mammalian cells are protected from complement induced damage by a family of cell membrane complement regulatory glycoproteins that downregulate activation of homologous complement on their cell surface. ${ }^{8}$ Protectin (CD59) is broadly distributed on cells of haemopoietic and non-haemopoietic origin ${ }^{7}$; it inhibits the formation of terminal complement complex by preventing the binding of C9 to $\mathrm{C} 5 \mathrm{~b}-8 .{ }^{10}{ }^{11}$ Decay accelerating factor (DAF $=\mathrm{CD} 55)$ inhibits the formation and promotes the catabolism of $\mathrm{C} 3$ and $\mathrm{C} 5$ convertases. ${ }^{12}$ Membrane cofactor protein $(\mathrm{MCP}=\mathrm{CD} 46)$, a widely distributed $\mathrm{C} 3 \mathrm{~b} / \mathrm{C} 4 \mathrm{~b}$ binding cell surface glycoprotein, acts indirectly by serving as cofactor for the enzymic degradation of $\mathrm{C} 3 \mathrm{~b}$ to C3bi by factor I. ${ }^{13}$

In a recent study, CD59 was shown to be confined to the apical surface of normal human colonic epithelium, MCP was intensely expressed basolaterally, whereas DAF occurred sporadically on the luminal surface. ${ }^{14}$ The expression of DAF and CD59 was increased in ulcerative colitis (UC) as well as in inflammatory controls. ${ }^{414}$ DAF expression was upregulated in a subset of colorectal adenomas and cancers. ${ }^{15}$ In another study, the human respiratory epithelium was reported to express CD59, $\mathrm{DAF}$, and MCP (but not complement receptor type 1) in normal mucosa, and immunohistochemical staining increased in inflammation and in lung cancer cells. ${ }^{16}$ Complement regulatory molecules are expressed throughout the female genital tract, ${ }^{17}$ and CD59 is strongly expressed on normal gingival epithelium and vascular endothelium in the underlying connective tissue. ${ }^{18}$

Little is known about the local protective measures operating against complement induced damage along the human gastrointestinal tract in health and disease. The aim of this study was to evaluate the expression and distribution of complement inhibitory molecules in the gastric and intestinal mucosa in normal controls and in chronic inflammatory diseases, including lesions associated with chronic $H$ pylori infection. ${ }^{19} 20$ We used immunohisto- 
Table 1 Clinicopathological information about patients with Crohn's disease (CD) or ulcerative colitis (UC)

\begin{tabular}{|c|c|c|c|c|c|c|c|}
\hline \multicolumn{4}{|c|}{ Patients } & \multicolumn{2}{|l|}{ Disease } & \multirow[b]{2}{*}{ Specimen site } & \multirow[b]{2}{*}{ Local inflammation ${ }^{\star}$} \\
\hline $\mathrm{No}$ & Age (y) & Sex & Medication & Diagnosis & Duration (y) & & \\
\hline 1 & 25 & $\mathrm{~F}$ & Sulphasalazine $3 \mathrm{~g}$ & $\mathrm{CD}$ & 11 & Ileum & $3+$ \\
\hline 2 & 22 & $\mathrm{~F}$ & Prednisolone $15 \mathrm{mg}$, mesalazine $2 \mathrm{~g}$ & $\mathrm{CD}$ & 6 & Ileum & $3+$ \\
\hline 3 & 27 & $\mathrm{~F}$ & Mesalazine $750 \mathrm{mg}$ & $\mathrm{CD}$ & 10 & Ileum & 0 \\
\hline 4 & 26 & $\mathrm{M}$ & None & $\mathrm{CD}$ & 9 & Ileum & $3+$ \\
\hline 5 & 46 & $M$ & Mesalazine $1 \mathrm{~g}$ & $\mathrm{CD}$ & 13 & Ileum & $2+$ \\
\hline 6 & 30 & M & Prednisolone $12.5 \mathrm{mg}$, mesalazine $1 \mathrm{~g}$ & $\mathrm{CD}$ & $<1$ & Ileum & $3+$ \\
\hline 7 & 38 & $\mathrm{~F}$ & Prednisolone $15 \mathrm{mg}$ & $\mathrm{CD}$ & 1 & Ileum & 0 \\
\hline 8 & 29 & M & Prednisolone $20 \mathrm{mg}$ & $\mathrm{CD}$ & 14 & Duodenum & 0 \\
\hline 9 & 43 & M & Prednisolone $12.5 \mathrm{mg}$, mesalazine $1 \mathrm{~g}$ & $\mathrm{CD}$ & 18 & Ileum & $2+$ \\
\hline \multirow[t]{2}{*}{10} & 27 & $\mathrm{~F}$ & Prednisolone $10 \mathrm{mg}$, azathioprine $100 \mathrm{mg}$, & & & & \\
\hline & & & metronidrazole $1600 \mathrm{mg}$ & $\mathrm{CD}$ & 3 & Colon & $2+$ \\
\hline 11 & 24 & $\mathrm{~F}$ & None & $\mathrm{CD}$ & 5 & Colon & $3+$ \\
\hline 12 & 38 & $\mathrm{~F}$ & Methylprednisolone $100 \mathrm{mg}$, azathioprine $100 \mathrm{mg}$ & $\mathrm{CD}$ & 6 & Colon & $3+$ \\
\hline 13 & 45 & $\mathrm{~F}$ & None & $\mathrm{CD}$ & 8 & Colon & $3+$ \\
\hline 14 & 26 & $\mathrm{~F}$ & Methylprednisolone $60 \mathrm{mg}$ & $\mathrm{CD}$ & 3 & Colon & $3+$ \\
\hline 15 & 71 & M & Prednisolone $10 \mathrm{mg}$, mesalazine $1.5 \mathrm{mg}$ & $\mathrm{CD}$ & 4 & Rectum & $2+$ \\
\hline 16 & 36 & $\mathrm{~F}$ & None & $\mathrm{CD}$ & 9 & Sigmoid colon & $2+$ \\
\hline 17 & 24 & $\mathrm{~F}$ & Prednisolone $10 \mathrm{mg}$ & $\mathrm{CD}$ & 22 & Ascending colon & $1+$ \\
\hline \multirow[t]{2}{*}{18} & 22 & M & Prednisolone $25 \mathrm{mg}$, azathioprine $100 \mathrm{mg}$, & & & & \\
\hline & & & sulphasalazine $2 \mathrm{~g}$ & $\mathrm{CD}$ & 6 & Rectum & $2+$ \\
\hline 19 & 45 & $M$ & Sulphasalazine $3 \mathrm{~g}$ & $\mathrm{UC}$ & 25 & Colon & $3+$ \\
\hline \multirow[t]{2}{*}{20} & 35 & $\mathrm{~F}$ & Prednisolone $60 \mathrm{mg}$, cyclosporin $800 \mathrm{mg}$, & & & & \\
\hline & & & sulphasalazine $2 \mathrm{~g}$ & $\mathrm{UC}$ & $<1$ & Colon & $3+$ \\
\hline 21 & 32 & $\mathrm{~F}$ & None & $\mathrm{UC}$ & 14 & Colon & $3+$ \\
\hline 22 & 48 & $\mathrm{~F}$ & Prednisolone $7.5 \mathrm{mg}$ & $\mathrm{UC}$ & 4 & Rectum & $3+$ \\
\hline 23 & 41 & $M$ & Hydrocortisone $40 \mathrm{mg}$ & UC & 23 & Colon & $3+$ \\
\hline 24 & 45 & $M$ & Sulphasalazine $3 \mathrm{~g}$ & $\mathrm{UC}$ & 25 & Colon & $3+$ \\
\hline
\end{tabular}

$\star$ Disease activity graded according to: 0 , normal mucosa; $1+$, mild inflammation, some crypt abscesses, slight structural changes; $2+$, moderate active inflammation, several crypt abscesses, moderate structural changes; and 3, severe active inflammation, superficial erosions, and notable structural changes.

chemistry with monoclonal antibodies (mAbs) on frozen and directly alcohol fixed tissue specimens to map the distribution of CD59, DAF, and MCP.

\section{Methods}

PATIENTS

Gastric mucosal biopsy specimens (one from the antrum and one from the body) were obtained endoscopically in each of 18 individuals attending an outpatient gastroenterology clinic for various abdominal complaints (seven women and 11 men; median age 43.5 years, range $20-73$ years). One patient had received triple therapy consisting of colloidal bismuth subcitrate, metronidazole, and tetracycline almost two years earlier for eradication of $H$ pylori. Additional specimens (one from the antrum and one from the body) were used for the immunohistochemical detection of $H$ pylori (see below). Archival gastric biopsy specimens (stored as paraffin blocks after ethanol fixation;

Table 2 Clinicopathological information about control patients with histologically normal mucosa

\begin{tabular}{|c|c|c|c|c|c|}
\hline No & Age (y) & Sex & Diagnosis & Specimen site & Type of specimen \\
\hline 1 & 67 & $\mathrm{~F}$ & Weight loss & Duodenum & Endoscopic \\
\hline 2 & 9 & $M$ & Chronic diarrhoea & Duodenum & Endoscopic \\
\hline 3 & 1 & $\mathrm{~F}$ & Dehydration & Duodenum & Endoscopic \\
\hline 4 & 1 & $\mathrm{~F}$ & $\begin{array}{l}\text { Obstipation and } \\
\text { diarrhoea }\end{array}$ & Duodenum & Endoscopic \\
\hline 5 & 2 & $\mathrm{~F}$ & Blood in stools & Duodenum & Endoscopic \\
\hline 6 & 68 & $M$ & Angiodysplasia & Duodenum & Endoscopic \\
\hline 7 & 38 & $\mathrm{~F}$ & Pancreas cancer & Duodenum & Resection \\
\hline 8 & 40 & $\mathrm{~F}$ & Pancreas cancer & Duodenum & Resection \\
\hline 9 & 33 & $\mathrm{~F}$ & Abdominal pain & Jejunum & Endoscopic \\
\hline 10 & 41 & $M$ & Diarrhoea & Transverse colon & Endoscopic \\
\hline 11 & 56 & $M$ & Diarrhoea & Ascending colon & Endoscopic \\
\hline 12 & 67 & $\mathrm{~F}$ & Arteriosclerosis & Rectum & Resection \\
\hline 13 & 41 & $\mathrm{~F}$ & Obstipation & Descending colon & Endoscopic \\
\hline 14 & 26 & $\mathrm{~F}$ & Obstipation & Colon & Endoscopic \\
\hline 15 & 66 & $\mathrm{M}$ & Normal control & Colon & Endoscopic \\
\hline 16 & 66 & $\mathrm{~F}$ & Normal control & Colon & Endoscopic \\
\hline
\end{tabular}

Normal mucosa was determined by an experienced pathologist on haematoxylin and eosin stained sections. see below) from three additional patients were also studied (obtained surgically from two patients (one operated on using Billroth II resection for gastric ulcer and one with severe kidney failure and gastritis) and by routine endoscopy from one patient operated on using Billroth II resection 28 years earlier). These specimens were included because the antral or gastric stump mucosa contained areas with intestinal metaplasia; they were examined separately and not included in the statistical analysis.

Biopsy specimens from the proximal small intestine were obtained from nine patients with coeliac disease (median age 17 years, range 3-67 years); six had total and three subtotal villous atrophy as determined histologically.

Distal ileal and colonic specimens were obtained surgically from 18 patients with Crohn's disease (CD) and six with chronic UC (table 1). The diagnoses were based on routine clinical, endoscopic, and histopathological criteria.

For normal controls, endoscopic biopsy or resection specimens were obtained from the duodenum, ileum, and colon of 11 women and five men without histological evidence of disease (table 2).

PREPARATION OF TISSUE SPECIMENS

Tissue specimens were immediately placed in ice chilled tissue culture medium (RPMI 1640; Gibco, Paisley, Scotland, UK) or in a $0.5 \%$ paraformaldehyde/lysine/periodate fixative and brought to the laboratory within two hours. The biopsy specimens were properly oriented on a thin slice of carrot for appropriate orientation and handling, embedded in OCT (Tissue-Tek; Miles Laboratories, Elkhart, IN, USA), snap frozen in liquid nitrogen, and stored at $-70^{\circ} \mathrm{C}$. Cryosections cut serially at $4 \mu \mathrm{m}$, were dried overnight at room 

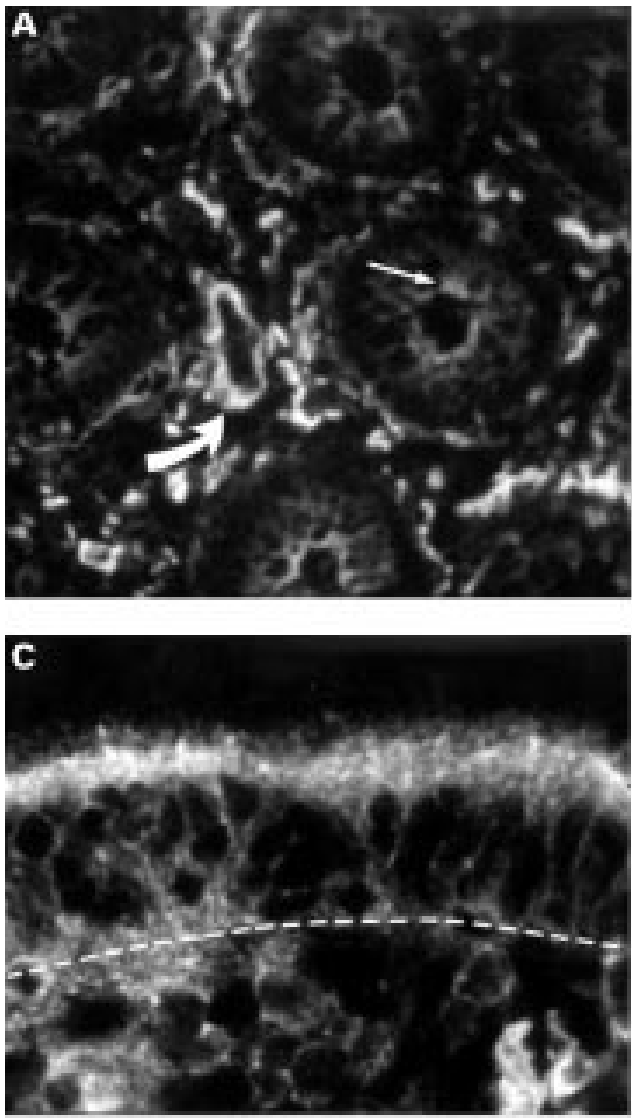

Figure 1 Immunofluorescence staining for protectin (CD59) in cryosections of mucosal tissue specimens. (A) In the normal stomach, CD59 is present in vessel endothelium (bowed arrow), extravascular tissue elements, and apically on epithelial cells of gastric body pits (arrow). (B) Parietal cells (arrow) show autofluorescence but do not express CD59. (C) In distal duodenum with coeliac disease (total villous atrophy) there is notable apical and some basolateral expression of CD59 on the surface epithelium (at the top) as well as on lamina propria cells (basement membrane indicated by broken line). (D) In crypts (bowed arrow) of normal colon, there is strong apical and weaker basolateral expression of CD59 on enterocytes but apparently not on goblet cells. Note also strong expression in the lamina

propria. Original magnifications: $A, B$, and $D, \times 400 ; C, \times$ 1000

temperature, post-fixed in acetone for $10 \mathrm{~min}$ utes, wrapped in aluminium foil, and stored at $-20^{\circ} \mathrm{C}$ until use.

Additional gastric specimens (one from the antrum and one from the body mucosa) and archival biopsy material had been fixed directly in cold $96 \%$ ethanol at $4^{\circ} \mathrm{C}$ for 24 hours and then embedded in paraffin wax at $56^{\circ} \mathrm{C}$ for three to four hours. ${ }^{21}$

TWO COLOUR IMMUNOFLUORESCENCE STAINING Cryosections were incubated for one hour with murine $\mathrm{mAb}$ to human CD59 (Brick 229; IgG2b, $1.1 \mathrm{mg} / \mathrm{l}$; IBGRL, Bristol, UK), DAF (Brick 110; IgG1, $2.1 \mathrm{mg} / 1$; IBGRL), or MCP (J4-48; IgG1, 1mg/1; Serotec, Oxford, UK). Serial dilutions of the mAbs were used to obtain an indication of the respective expression level of the antigens. Sections were next incubated for one hour with rabbit antiserum to cytokeratin (1:100 dilution $)^{22}$ or factor VIII related antigen (1:1400 dilution; DAKO, Glos-
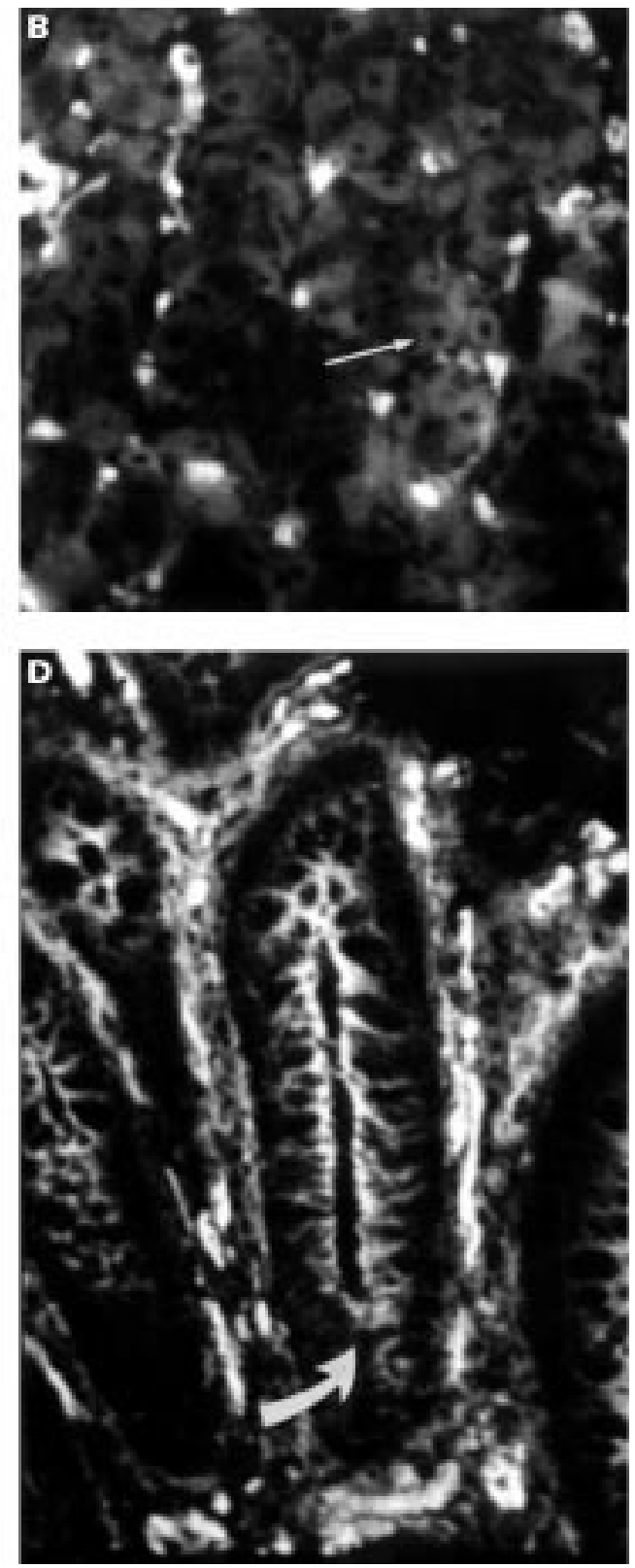

trup, Denmark) followed by biotinylated horse anti-mouse IgG (2 mg/l; Vector Laboratories, Burlingame, CA, USA) for 1.5 hours, and then fluorescein isothiocyanate (FITC) conjugated swine anti-rabbit IgG (1:160 dilution; DAKO) mixed with streptavidin-Texas red conjugate (1:200 dilution; Gibco-BRL, Gaithersburg, $\mathrm{MD}$, USA) for 30 minutes.

Serial paraffin wax sections, cut at $5 \mu \mathrm{m}$ from directly ethanol fixed specimens, were dewaxed and incubated for 20 hours at room temperature with the same concentrations of primary mAbs as mentioned above. The rest of the immunohistochemical staining sequence was the same except that the incubation of biotinylated horse anti-mouse IgG was prolonged to three hours.

All antibody reagents were appropriately diluted in isotonic phosphate buffered saline (PBS), $\mathrm{pH} 7.5$, containing bovine serum albu$\min (12.5 \mathrm{~g} / \mathrm{l})$. Incubations took place at room temperature with intervening three minute 
Table 3 Epithelial expression of protectin (CD59) in histologically normal controls and inflamed mucosae

No of specimens with different immunostaining scores *

\begin{tabular}{|c|c|c|c|c|c|}
\hline & \\
\hline & 0 & $1+$ & $2+$ & $3+$ & Total \\
\hline \multicolumn{6}{|l|}{ Stomach } \\
\hline Normal body & 2 & 4 & 2 & 0 & 8 \\
\hline Normal antrum & 0 & 5 & 3 & 0 & 8 \\
\hline Inflamed body $\dagger$ & 0 & 1 & 9 & 0 & 10 \\
\hline Inflamed antrum $\neq$ & 0 & 3 & 7 & 0 & 10 \\
\hline \multicolumn{6}{|l|}{ Small intestine } \\
\hline Normal duodenum & 3 & 6 & 0 & 0 & 9 \\
\hline Coeliac disease $\nmid$ & 0 & 5 & 4 & 0 & 9 \\
\hline Crohn's disease $₫$ & 0 & 5 & 3 & 1 & 9 \\
\hline \multicolumn{6}{|l|}{ Colon } \\
\hline Normal & 0 & 1 & 6 & 0 & 7 \\
\hline Crohn's disease $\neq$ & 0 & 1 & 8 & 0 & 9 \\
\hline Ulcerative colitis $\ddagger$ & 0 & 1 & 5 & 0 & 6 \\
\hline
\end{tabular}

$\star$ No detectable staining, 0 ; specific staining of fewer than half of the cells, $1+$; specific staining of more than half of the cells, $2+$; and strong continuous staining, $3+$.

†Significantly increased staining compared with normal mucosa $(\mathrm{p}=0.02)$.

$\ddagger$ Staining levels were not significantly increased compared with normal mucosa.

SComparison with normal tissue not possible.

rinses in PBS. Murine mAbs directed towards keyhole limpet haemocyanin (IgG2a; Becton Dickinson, Mountain View, CA, USA) and black ringspot nepovirus (IgG1; Robert Burns, Edinburgh, Scotland, UK) applied at a working concentration comparable with those indicated above, or secondary reagents without application of primary mAbs, provided negative controls.

After the final PBS rinse, the sections were mounted directly (without drying) in buffered polyvinyl alcohol ( $\mathrm{pH} 8.7)$, which retards fluorescence fading of all fluorochromes during microscopy and section storage. ${ }^{23}$

DETERMINATION OF H PYLORI INFECTION

To determine the presence of $H$ pylori on gastric mucosa, a rabbit antiserum to $H$ pylori (1:10 dilution; DAKO) was applied for 20 hours at room temperature. This reagent distinguished $H$ pylori from other curved bacteria present in the stomach and had a sensitivity of $100 \%$ and a specificity of $94 \%$ compared with cultivation results. ${ }^{24}$ FITCconjugated swine anti-rabbit IgG $(1: 160$; DAKO) was applied for three hours as secondary reagent. Omission of the primary antiserum provided a negative control. After mounting, the tissue sections were examined by fluorescence microscopy.

Table 4 Epithelial expression of DAF (CD55) in histologically normal controls and inflamed mucosae

\begin{tabular}{|c|c|c|c|c|c|}
\hline & \multicolumn{5}{|c|}{ No of specimens with different immunostaining scores * } \\
\hline & 0 & $1+$ & $2+$ & $3+$ & Total \\
\hline \multicolumn{6}{|l|}{ Stomach } \\
\hline Normal body & 8 & 0 & 0 & 0 & 8 \\
\hline Normal antrum & 8 & 0 & 0 & 0 & 8 \\
\hline Inflamed body & 8 & 1 & $1 \dagger$ & 0 & 10 \\
\hline Inflamed antrum & 6 & $3+$ & $1 \dagger$ & 0 & 10 \\
\hline \multicolumn{6}{|l|}{ Small intestine } \\
\hline Normal duodenum & 6 & 2 & 1 & 0 & 9 \\
\hline Coeliac disease $\ddagger$ & 0 & 2 & 7 & 0 & 9 \\
\hline Crohn's disease $\$$ & 3 & 0 & 3 & 3 & 9 \\
\hline \multicolumn{6}{|l|}{ Colon } \\
\hline Normal & 6 & 1 & 0 & 0 & 7 \\
\hline Crohn's disease $\ddagger$ & 1 & 2 & 4 & 2 & 9 \\
\hline Ulcerative colitis $\ddagger$ & 0 & 0 & 1 & 5 & 6 \\
\hline
\end{tabular}

${ }^{\star}$ No detectable staining, 0 ; specific staining of fewer than half of the cells, $1+$; specific staining of more than half of the cells, $2+$; and strong continuous staining, $3+$.

tDAF expression was shown mainly by intestinal metaplasia.

$\ddagger$ Significantly increased staining compared with normal mucosa $(p \leqslant 0.003)$.

$\int$ Comparison with normal tissue not possible.
MICROSCOPY AND PHOTOGRAPHY

Parallel tissue sections from each specimen were stained with haematoxylin and eosin and graded for inflammation by the same observer. Gastritis was graded according to the presence and density of mononuclear cells and neutrophils in the lamina propria as well as in the epithelium according to the Sydney system. ${ }^{25}$ Intestinal metaplasia indicated the presence of intestinal glandular tissue. The inflammation of UC and CD mucosae was graded on a $0-3$ scale according to the following criteria: 0 , normal mucosa; $1+$, mild inflammation, some crypt abscesses, slight structural changes; $2+$, moderate active inflammation, several crypt abscesses, moderate structural changes; and 3, severe active inflammation, superficial erosions and notable structural changes.

The immunostained sections were examined by the same investigator in a Leitz DMR-DXE microscope equipped with a Ploem-type vertical illuminator and Leitz DMRD camera system (Leica, Wetzlar, Germany). A dual filter for the simultaneous observation of red (Texas red) and green (FITC) emission identified coexpression of two markers as yellow. Pictures were recorded on Ektachrome 400 ISO daylight film pushed to 800 ISO.

Epithelial marker expression was semiquantitatively scored on a four point scale: no detectable staining (0); specific staining of fewer than half of the cells $(1+)$; specific staining of more than half of the cells $(2+)$; and strong continuous staining $(3+)$. Specific staining of elastic fibrils, muscular tissue, and vessels walls was also recorded (without grading).

\section{STATISTICAL ANALYSIS}

The Mann-Whitney $U$ test was used to compare marker expression at various tissue sites and between different groups of patients. Two-tailed $\mathrm{p}$ values smaller than 0.05 were considered statistically significant.

\section{Results}

INFECTION STATUS AND DEGREE OF PATHOLOGY IN GASTRITIS

Of the 18 patients who provided endoscopic tissue specimens from the stomach, eight were considered to be infected with $H$ pylori as determined by immunofluorescence in situ. All biopsy specimens from $H$ pylori-positive individuals were inflamed. Gastritis was found in both antrum and body specimens of two $H$ pylori-negative patients, including the patient who had received triple therapy two years earlier. In this patient, grade 1 inflammation was detected in both biopsy specimens, but neutrophils were absent. Intestinal metaplasia was present in the antrum, but not in the body biopsy specimen. Normal mucosae were found in the remaining eight uninfected patients. Intestinal metaplasia was present in three specimens (two antrum, one body) from one uninfected and two infected individuals with gastritis. 

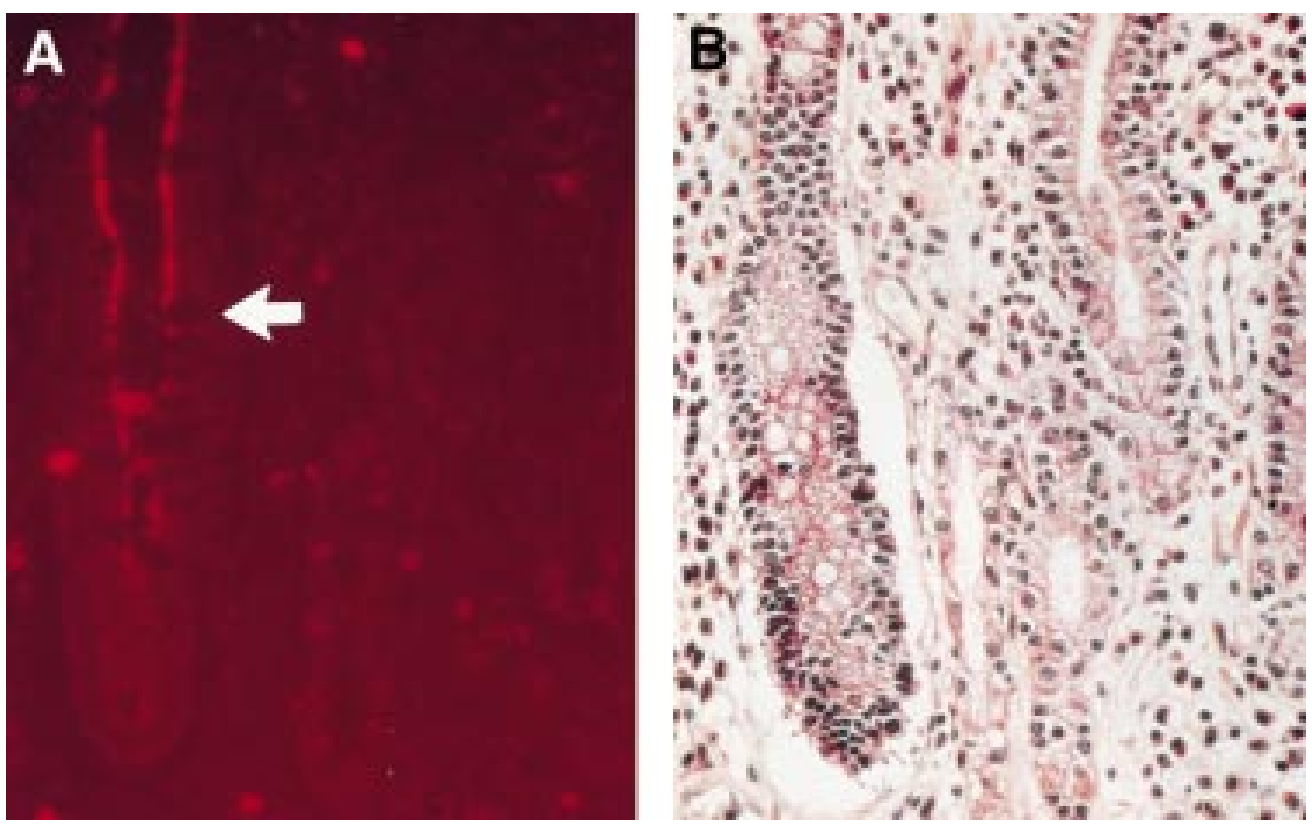

Figure 2 (A) Immunofluorescence for $D A F$ (CD55) in sections of ethanol fixed specimen from the gastric antrum of a patient with $H$ pylori infection, gastric ulcer, and extensive metaplasia. (B) Adjacent haematoxylin and eosin stained section shown for morphological orientation. The foveolar pit on the left shows intestinal metaplasia, with apical CD55 expression on enterocytes, whereas goblet cells (arrow) are negative, producing a gap in the fluorescent luminal brim. Gastric pit epithelium elsewhere in the section is completely CD55-negative. Original magnifications: $A$ and $B, \times 400$.

PROTECTIN (CD59)

Strong CD59 expression was observed in vessel endothelium and extravascular tissue elements throughout the gastrointestinal tract (fig 1A), whereas it showed only weak expression apically on epithelial cells of the gastric pits, generally more strongly on cells facing the stomach lumen. The staining intensity was increased in the surface and pit epithelium of inflamed body mucosa (median grade $2 v$ grade $1, p=0.02$ ), but not in inflamed antral specimens (median grade $2 v$ grade $1, \mathrm{p}=0.3$ ) compared with normal controls (table 3 ). Epithelial elements of intestinal metaplasia also showed CD59 expression. Conversely, the parietal cells of gastric glands in normal as well as inflamed body specimens were completely negative (fig 1B).

In the normal distal duodenum, weak staining for CD59 was seen apically on both villus and crypt epithelial cells, with increased

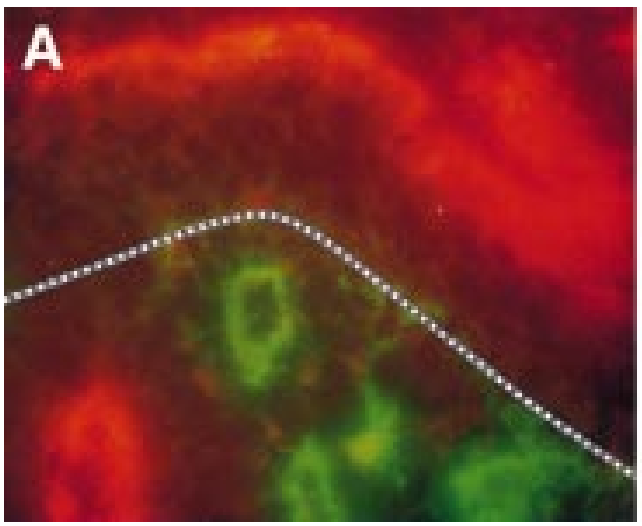

Figure 3 Two colour immunofluorescence staining for DAF (CD55, Texas red) and factor VIII related antigen (FITC, green) in cryosection from inflamed colon of patient with Crohn's disease $(A)$ or from distal duodenum of a patient with coeliac disease (B). Notable apical CD55 expression is seen on the colonic surface epithelium and on duodenal crypt epithelium (basement membrane indicated by broken line). Subepithelial blood vessels, identified by the expression of von Willebrand factor, do not express CD55 in either tissue. Original magnification: $A$ and $B, \times 1000$. expression towards the upper part of the villi. There was significantly increased epithelial staining in coeliac disease $(p=0.02$, fig $1 \mathrm{C})$ compared with specimens from the distal duodenum of normal controls. Epithelial staining for CD59 also appeared in CD of the terminal ileum (table 3).

In the normal colon, significantly stronger epithelial expression of CD59 was seen (fig 1D) than in the normal distal duodenum (median grade $2 v$ grade $1, \mathrm{p}=0.001$ ) and the normal gastric body (median grade $2 v$ grade 1 , $\mathrm{p}=0.04)$. The intensity was not increased in the colon of patients with UC or CD compared with normal, however ( $\mathrm{p}=0.9$ for both groups). Application of serially diluted antiCD59 mAb (from $1.1 \mathrm{mg} / 1$ to $14 \mu \mathrm{g} / \mathrm{l}$ ) showed no apparent difference in antigen expression in the colon of patients with UC or CD compared with normal.

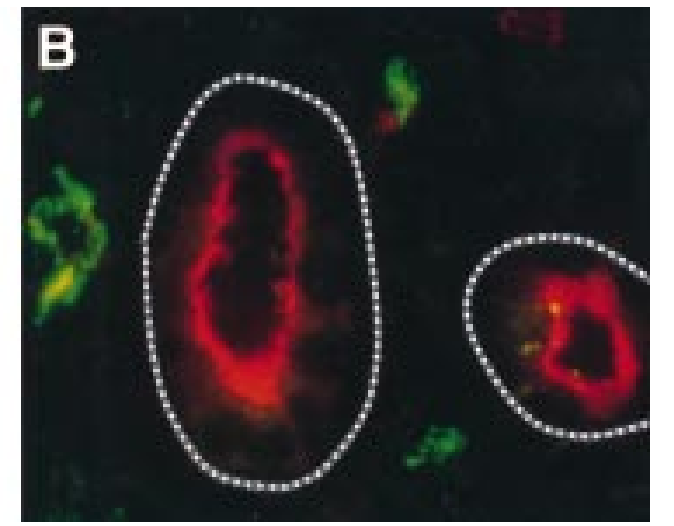



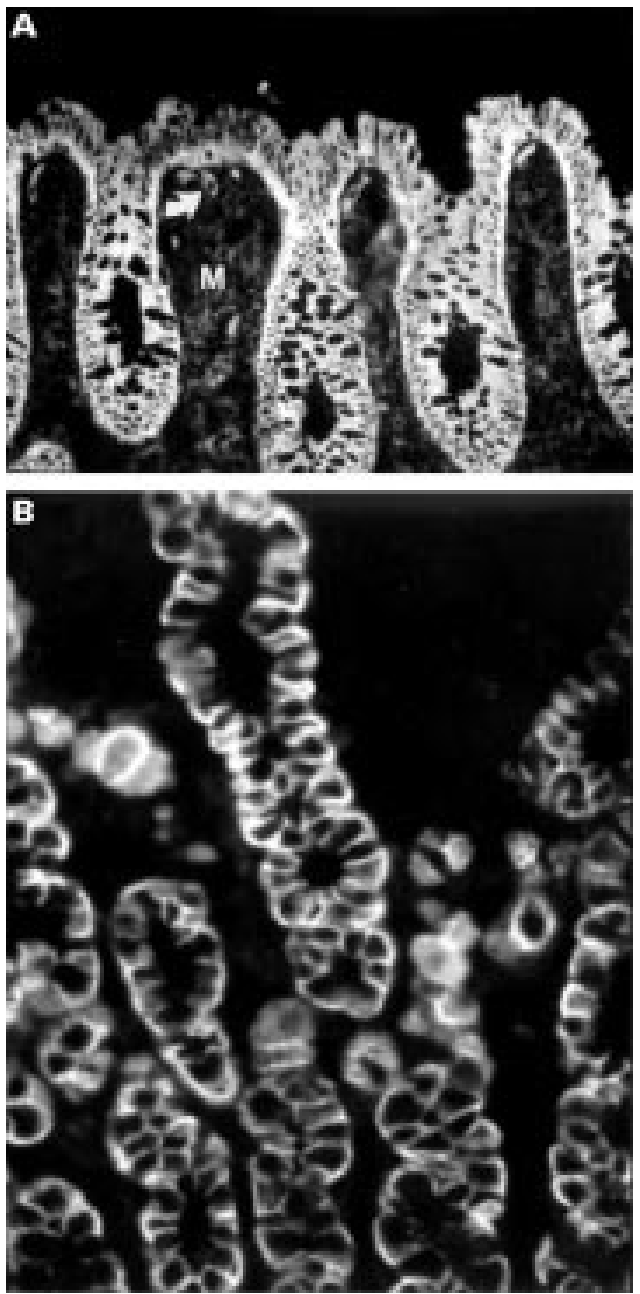

Figure 4 Immunofluorescence staining of MCP (CD46) in mucosal sections. (A) In normal colonic mucosa, vascular endothelium (arrow), extravascular tissue (M), and in particular epithelial cells show intense CD46 expression. (B) Distinct basolateral expression of CD46 is evident on parietal cells in inflamed gastric body mucosa. Original magnifications: $A, \times 250 ; B, \times 400$.

DAF (CD55)

Some inflammatory cells in the lamina propria and endothelial cells were weakly positive for CD55. The lamina propria stroma did not express CD55 in the mucosae examined, neither did the epithelium of normal gastric mucosa. CD55-positive gastric pit epithelium was found in two patients with gastritis. However, the epithelial elements of intestinal metaplasia present in six biopsy specimens (three frozen, three ethanol fixed) from six separate patients regularly expressed CD55 apically, unlike the adjacent gastric epithelium (fig 2, table 4). Goblet cells of intestinal metaplasia did not express CD55.

The villus epithelium of normal duodenum was negative for CD55 except in one case, but the apical face of crypt epithelium was generally positive. In coeliac disease, apical expression of CD55 was more extensive than in the normal duodenum $(\mathrm{p}=0.002)$. Strong expression (grades $2+$ and $3+$ ) was found in all of six inflamed ileal CD specimens. Neither inflammation nor CD55 expression was present in the ileal specimens from CD patients nos 3 and 7 or in the duodenal specimen from CD patient no 8 (table 1 ).

The normal colon epithelium did not express CD55 except in one case where it was sporadically seen on the apical face of crypt epithelium. By contrast, notable CD55 expression occurred in colonic specimens from all UC patients and in colonic specimens from eight of nine CD patients (fig 3, table 4).

MCP (CD46)

In contrast with CD59 and CD55, intense expression was observed basolaterally for CD46 on all epithelial cells of gastric pits and glands, as well as of intestinal crypts and villi, in both non-inflamed and inflamed mucosae throughout the gastrointestinal tract (fig 4A). Cells of proliferative zones were also positive, as were parietal cells in the gastric body (fig 4B). CD46 was expressed on some inflammatory cells in the lamina propria, and on endothelial cells, but the extracellular matrix was generally negative. Application of serially diluted anti-CD46 mAb (from $1 \mathrm{mg} / 1$ to 10 $\mu \mathrm{g} / \mathrm{l})$ showed no apparent difference in CD46 expression level at different sites or between non-inflamed and inflamed mucosae.

\section{Discussion}

In this comparative immunohistochemical study, we demonstrated that the cell membrane complement regulatory glycoproteins protectin (CD59) and MCP (CD45) were widely expressed in histologically normal mucosae along the human gastrointestinal tract. To our knowledge, such a systematic topographical comparison has not been previously performed. We also found that the expression of epithelial DAF (CD55), and to some extent protectin, was upregulated in chronic gastritis, coeliac disease, and inflammatory bowel disease. In the stomach, areas with intestinal metaplasia were often positive for DAF, unlike the adjacent gastric epithelium. In normal colon mucosa, protectin expression apically on the epithelium was more intense than in the normal duodenum and stomach. The colon is permanently inhabited by a large number of various micro-organisms; in teleological terms therefore epithelial defence against activated complement probably needs to be augmented compared with that in the normal relatively sterile small intestine and stomach.

DAF appeared apically on the crypt cells in the normal small intestine, but otherwise it was absent from the epithelium of normal gastric and small intestinal mucosae. DAF was expressed sporadically in only one of the individuals with normal colons. However, we found notably increased DAF expression in UC as reported previously, ${ }^{14}$ and extended this finding by showing similar epithelial upregulation of DAF in coeliac disease as well as in ileal and colonic CD. DAF is a glycan phosphatidylinositol anchored protein, and its expression therefore is restricted to the apical surface membrane of epithelial cells ${ }^{26}$; this feature increased with a gradient from negative progenitor cells to differentiated more mature 
cells. Undifferentiated cells also lacked protectin but always expressed MCP.

Cytokines produced in intestinal inflammatory lesions ${ }^{27}$ may upregulate DAF and CD59 expression in the epithelium, because intestinal epithelial cells are in dynamic equilibrium with adjacent immune and mesenchymal cells. Proinflammatory and immunoregulatory cytokines such as tumour necrosis factor $\alpha$, interleukin (IL) $1 \beta$, and low concentrations of interferon $\gamma(\mathrm{IFN}-\gamma)$ enhance in a dose dependent manner the constitutive expression of protectin on the human colonic adenocarcinoma cell line HT29. ${ }^{28} \mathrm{IL}-4$, and to a lesser degree lipopolysaccharides and IL-1 $\beta$, upregulate DAF expression, but not MCP, on human endothelial cells. ${ }^{29}$ Epithelial protectin expression in the normal colon was relatively strong and we did not observe increased levels of protectin in UC and CD of the colon. This was not in agreement with an earlier study where increased protectin expression in UC was found. ${ }^{14}$ However, the expression was significantly upregulated in coeliac disease and body gastritis. IFN- $\gamma$ appears to be the most important cytokine secreted by mucosal $\mathrm{T}$ cells in coeliac disease, ${ }^{30}$ and an increase in the number of IFN- $\gamma$ secreting cells in $H$ pylori-positive and -negative gastritis has been reported. ${ }^{31}$ In contrast with protectin and DAF, intense expression was observed for MCP basolaterally on epithelial cells both in inflamed and uninflamed stomach as well as intestine. Application of serially diluted $\mathrm{mAb}$ showed no upregulation of MCP in inflamed mucosa compared with normal mucosa, in agreement with constitutive rather than cytokinedependent expression of MCP. ${ }^{29}$

Parietal cells of the gastric body expressed neither protectin nor DAF, suggesting that these cells are vulnerable targets for complement attack. An activation neoepitope of the terminal complement complex has been located near and surrounding the gastric glands significantly more often in inflamed than in uninflamed specimens, in both the body and antral mucosa. ${ }^{6}$ Therefore parietal cell injury by complement activation could contribute to the development of atrophic gastritis, either induced via the classical activation pathway by parietal cell IgG autoantibodies ${ }^{32}$ or because of innocent bystander lysis. Parietal cell antibodies appear during follow up in simple $H$ pylori gastritis and may cause progression of body atrophy. ${ }^{33} H$ pylori induced anti-Lewis ${ }^{y}$ antibody cross reacts with the glycosylated $\beta$-chain of human gastric $\mathrm{H}^{+}, \mathrm{K}^{+}$-ATPase, the parietal cell proton pump, and may be a link to autoimmunity in chronic gastritis. ${ }^{34}$

Subepithelial deposition of terminal complement complex has been observed in most patients with coeliac disease. ${ }^{5}$ Incomplete protection of the basolateral face of epithelial cells may lead to cell damage and compensatory crypt cell hyperproliferation. Furthermore, activated $\mathrm{C} 3 \mathrm{~b}$ deposited apically on the surface epithelium has been observed in involved UC mucosa. ${ }^{2}$ The expression of DAF on the apical face of epithelial cells in UC could provide some protection against complement induced damage from the luminal side. ${ }^{3}$

Apical epithelial DAF expression was seen preferentially in intestinal metaplasia, which might be of importance for the progression of such lesions and their potential for neoplastic transformation. $H$ pylori infection is a significant risk factor for development of atrophic gastritis and intestinal metaplasia. ${ }^{19}$ Perhaps bacterial overgrowth as a result of hypochlorhydria in the atrophic stomach results in continuous epithelium related complement activation; and cells of the intestinal phenotype may be better suited to survive in this hostile environment than the surrounding gastric epithelium. Over time, extensive intestinal metaplasia could be an adverse result. In fact, it is believed that most gastric adenocarcinomas are derived from such metaplastic epithelial elements, ${ }^{35}$ and this development might involve a positive selection pressure related to protection against complement attack.

In conclusion, cell membrane complement regulatory glycoproteins were found to be widely expressed by the epithelium in healthy mucosae along the human gastrointestinal tract. However, the pattern of complement inhibitory molecules differed at various sites and in association with inflammatory diseases, suggesting a variable protective potential. The role of complement inhibitory molecules in protection against epithelial and glandular destruction in inflammatory diseases of the gastrointestinal tract remains undetermined, but it is of considerable interest that areas of intestinal metaplasia of the stomach often expressed DAF, unlike the adjacent gastric tissue, and that parietal cells appeared to be relatively poorly protected. The cost of the colour plate was kindly carried by Wyeth Lederle.

We thank members of the staff at the Gastroenterology Section of the Medical Department at Lovisenberg Hospital and Rikshospitalet, Oslo, for their cooperation, and Dr Line Bjørge for excellent advice and provision of antibodies. Drs Jarle Rugtveit, Olav Fauna, Kjell Kett, and Helge Scott are acknowledged for making tissue specimens available. Irrelevant IgG1 antibody was a gift from Dr Robert Burns, Edinburgh, Scotland. The excellent assistance of the LIIPAT technical staff is gratefully acknowledged. Financial support was provided by the Norwegian Cancer Society, the Research Council of Norway, and Anders Jahre's Foundation. The cost of the colour plates was kindly carried by Wyeth Lederle.

1 Frank MM, Fries LF. The role of complement in inflammation and phagocytosis. Immunol Today 1991;12:322-6

2 Halstensen TS, Mollnes TE, Garred P, et al. Epithelial deposition of immunoglobulin G1 and activated complement (C3b and terminal complement complex) in ment (C $3 \mathrm{~b}$ and terminal complement complex)

3 Halstensen TS, Mollnes TE, Garred P, et al. Surface epithelium related activation of complement differs in Crohn's disease and ulcerative colitis. [Correction appears in Gut disease and ulcerative colitis. [Correct

4 Ueki T, Mizuno M, Uesu T, et al. Distribution of activated complement, $\mathrm{C} 3 \mathrm{~b}$, and its degraded fragments, $\mathrm{iC} 3 \mathrm{~b} /$ C3dg, in the colonic mucosa of ulcerative colitis (UC). Clin Exp Immunol 1996;104:286-92.

5 Halstensen TS, Hvatum M, Scott $\mathrm{H}$, et al. Association of subepithelial deposition of activated complement and immunoglobulin $\mathrm{G}$ and $\mathrm{M}$ response to gluten in celiac disease. Gastroenterology 1992;102:751-9.

6 Berstad AE, Brandtzaeg P, Stave R, Halstensen TS. Epithelium related deposition of activated complement in Helicobacter pylori associated gastritis. Gut 1997;40:196-203.

7 Davies A, Lachmann PJ. Membrane defence against complement lysis: the structure and biological properties of CD59. Immunol Res 1993;12:258-75.

8 Lachmann PJ. The control of homologous lysis. Immunol Today 1991;12:312-15.

9 Meri S, Waldmann H, Lachmann PJ. Distribution of protectin (CD59), a complement membrane attack inhibitor, in normal human tissues. Lab Invest 1991;65:532-7. 
10 Okada N, Harada R, Fujita T, Okada H. A novel membrane glycoprotein capable of inhibiting membrane attack by glycoprotein capable of inhibiting membrane attack

11 Rollins SA, Sims PJ. The complement-inhibitory activity of CD59 resides in its capacity to block incorporation of C9 into membrane C5b-9. F Immunol 1990;144:3478-83.

12 Fujita $\mathrm{T}$, Inoue $\mathrm{T}$, Ogawa $\mathrm{K}$, et al. The mechanism of action of decay-accelerating factor (DAF). DAF inhibits the assembly of $\mathrm{C} 3$ convertases by dissociating $\mathrm{C} 2 \mathrm{a}$ and $\mathrm{Bb} . \mathcal{F}$ Exp Med 1987;166:1221-8.

13 Liszewski MK, Post TW, Atkinson JP. Membrane cofactor protein (MCP or CD46): newest member of the regulators
of complement activation gene cluster. Annu Rev Immunol 1991;9:431-55.

14 Uesu T, Mizuno M, Inoue $\mathrm{H}$, et al. Enhanced expression of decay accelerating factor and CD59/homologous restriction factor 20 on the colonic epithelium of ulcerative colitis. Lab Invest 1995;72:587-91.

15 Koretz K, Brüderlein S, Henne C, Möller P. Decayaccelerating factor (DAF, CD55) in normal colorectal accelerating factor (DAF, CD55) in normal colorectal 810-4.

16 Varsano S, Frolkis I, Ophir D. Expression and distribution of cell-membrane complement regulatory glycoproteins along the human respiratory tract. Am $\mathcal{F}$ Respir Crit Care Med 1995;152:1087-93.

17 Jensen TS, Bjorge L, Wollen AL, Ulstein M. Identification of the complement regulatory proteins CD46, CD55, and CD59 in human fallopian tube, endometrium, and cervical mucosa and secretion. Am $\mathcal{F}$ Reprod Immunol 1995;34:1-9.

18 Rautemaa R, Meri S. Protection of gingival epithelium against complement-mediated damage by strong expression of the membrane attack complex inhibitor protectin (CD59). F Dent Res 1996;75:1-7.

19 Kuipers EJ, Uyterlinde AM, Peña AS, et al. Long-term sequelae of Helicobacter pylori gastritis. Lancet 1995;345: 1525-8.

20 Genta RM. Helicobacter pylori as a promoter of intestinal metaplasia and gastric cancer: an alluring hypothesis in 7(Suppl) $1: 25-30$.

21 Brandtzaeg P. Mucosal and glandular distribution of immunoglobulin components. Immunohistochemistry with a cold ethanol-fixation technique. Immunology 1974;26:1101-14

22 Huitfeldt HS, Brandtzaeg P. Various keratin antibodies produce immunohistochemical staining of human myocardium and myometrium. Histochemistry 1985;83:381-9.
23 Valnes K, Brandtzaeg P. Retardation of immunofluorescence fading during microscopy. F Histochem Cytochem 1985;33:755-61.

24 Andersen LP, Holck S, Povlsen CO. Campylobacter pylori detected by indirect immunohistochemical technique. APMIS 1988;96:559-64.

25 Price AB. The Sydney System: histological division. 7 Gastroenterol Hepatol 1991;6:209-22.

26 Nicholson-Weller A. Decay accelerating factor (CD55). Curr Top Microbiol Immunol 1992;178:7-30.

27 Sartor RB. Cytokines in intestinal inflammation: pathophysiological and clinical considerations. Gastroenterology 1994;106:533-9.

28 Bjorge L, Jensen TS, Ulvestad E, et al. The influence of tumour necrosis factor- $\alpha$, interleukin- $1 \beta$ and interferon- $\gamma$ on the expression and function of the complement regulatory protein CD59 on the human colonic adenocarcinoma cell line HT29. Scand f Immunol 1995;41:350-6.

29 Moutabarrik A, Nakanishi I, Namiki M, et al. Cytokinemediated regulation of the surface expression of complemediated regulation of the surface expression of comple-
ment regulatory proteins, CD46(MCP), CD55(DAF), and ment regulatory proteins, CD46(MCP), CD55(DAF), and CD59 on human vascular endoth
Cytokine Research 1993;12:167-72.

30 Nilsen EM, Lundin KE, Krajci P, et al. Gluten specific, HLA-DQ restricted $T$ cells from coeliac mucosa produce cytokines with Th1 or Th0 profile dominated by interferon

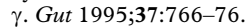

31 Karttunen R, Karttunen T, Ekre HT, MacDonald TT, Interferon $\gamma$ and interleukin 4 secreting cells in the gastric antrum in Helicobacter pylori positive and negative gastritis. Gut 1995;36:341-5.

32 Negrini R, Savio A, Poiesi C, et al. Antigenic mimicry between Helicobacter pylori and gastric mucosa in the pathogenesis of body atrophic gastritis. Gastroenterology 1996;111:655-65.

33 Valle J, Kekki M, Sipponen P, et al. Long-term course and consequences of Helicobacter pylori gastritis: results of a 32-year follow-up study. Scand f Gastroenterol 1996;31: 546-50.

34 Appelmelk BJ, Simoons-Smit I, Negrini R, et al. Potential role of molecular mimicry between Helicobacter pylori lipopolysaccharide and host Lewis blood group antigens in autoimmunity. Infect Immun 1996;64:2031-40.

35 Hattori T. Development of adenocarcinomas in the stomach. Cancer 1986;57:1528-34. 